\title{
Redefining Goods Movement: Building an Ecosystem for the Introduction of Heavy-Duty Battery-Electric Vehicles
}

\author{
Dawn Fenton and Aravind Kailas *
}

check for

updates

Citation: Fenton, D.; Kailas, A

Redefining Goods Movement:

Building an Ecosystem for the

Introduction of Heavy-Duty

Battery-Electric Vehicles. World Electr.

Veh. J. 2021, 12, 147. https://doi.org/

10.3390/wevj12030147

Academic Editors: Joeri Van Mierlo,

Aymeric Rousseau and

Genevieve Cullen

Received: 24 July 2021

Accepted: 27 August 2021

Published: 7 September 2021

Publisher's Note: MDPI stays neutral with regard to jurisdictional claims in published maps and institutional affiliations.

Copyright: (c) 2021 by the authors. Licensee MDPI, Basel, Switzerland. This article is an open access article distributed under the terms and conditions of the Creative Commons Attribution (CC BY) license (https:// creativecommons.org/licenses/by/ $4.0 /)$.
Volvo Group North America, 2900 K St. NW, South Building, Suite 410, Washington, DC 20007, USA; dawn.fenton@volvo.com

* Correspondence: aravind.kailas@volvo.com

\begin{abstract}
This article reviews the Volvo Low-Impact Heavy Green Transport Solution (LIGHTS) project, a multifaceted public-private partnership in Southern California, and provides some early insights and a model for successful fleet adoption of Class 8 battery-electric trucks. This paradigm shift in commercial trucking is emerging, forcing greater interdependence among many stakeholders -fleets, truck manufacturers, and policymakers-not currently engaged in the traditional heavy-duty commercial truck market. The many perspectives from this article such as lead times and costs associated with the deployment of charging infrastructure, developing the workforce to support largescale deployments, and the need for market development incentives from the government can be used to inform the programs and policies of California and other states seeking to follow their lead.
\end{abstract}

Keywords: electric vehicles; heavy duty; charging infrastructure; government; policy; zero emission

\section{Paradigm Shift in Commercial Trucking}

The transition to greater use of electric-powered vehicles, to mix metaphors, has picked up steam. Electric passenger car sales in the US grew from 17,763 to 326,644 between 2010 and 2019 [1], while in this same timeframe, hybrid buses grew from $7 \%$ to $17.7 \%$ of all transit buses sold [2]. During the last few years, there has been growing anticipation about similar trajectories in the commercial truck market. Greater utilization of battery-electric commercial trucks will improve working conditions and simplify vehicle maintenance, in addition to bringing larger societal benefits, such as noise reductions and air quality improvements, especially in crowded urban areas and freight corridors.

Unfortunately, market penetration of electric trucks is moving much more slowly, especially in the commercial trucking sector, which depends on batteries with high energy density and commercial customers with different purchase motivations. While there is frustration among some stakeholders at the slow pace of progress, it is important to realize the industry is on the cusp of a complete paradigm shift in commercial trucking, one with unmatched impact since the introduction of the diesel engine in 1893 [3].

The diesel engine has rightly been called the workhorse of the economy and has maintained its leadership as the heavy-duty powertrain of choice for more than 100 years due in part to the unparalleled energy density of diesel fuel [4]. Since 1998, diesel engines have reduced particulate matter (PM) and Nitrogen Oxides (NOx) emissions by 98\% [5], yet these technological advancements have had relatively few operational implications for truck drivers. With the advent of this anticipated shift to electric battery-powered trucks, commercial fleets must plan for both increased vehicle cost and significant operational impacts to their business, including fueling, maintenance, and route optimization.

Diesel is a ubiquitous fuel, with roughly 55\% of retail fueling stations nationwide offering diesel fuel [6]. In April 2021, Daimler Trucks North America (DTNA) and Portland General Electric (PGE) opened "Electric Island," the first public truck charging station [7]. There are a small number of others under development; however, this lack of public 
charging options means commercial fleets must consider multiple implications of their purchasing and fueling decisions. Fleets can expect sharp learning curves to understand vehicle operation, maintenance, power needs, and the cost and time for charging equipment procurement and installation. Beyond these initial infrastructure considerations, there are also other more complex factors to be considered, such as the impact of charging time and speed on fuel costs, route optimization, battery life, and the seamless integration of electric trucks into existing operations.

This paradigm shift will complicate fleet operational decisions in many ways, and it is imperative for policymakers to understand these considerations. All too often, assumptions on penetration rates of electric trucks are extrapolated from the light-duty electric car market, with technology advocates and policymakers assuming familiarity and growth in electric cars will facilitate a quicker acceptance of commercial electric trucks. Seeing the first Class 8 electric trucks in commercial operation can feed unrealistic expectations for an exponential growth rate. The truth is that the motivations for commercial trucking (fleets and independent operators) are vastly different from car owners, based more dispassionately on uptime and total cost of ownership (TCO) rather than the social perceptions of electric cars ownership. Maybe most importantly, the overall cost of owning and operating electric trucks must be equal (at the very least) or better (preferable) than today's diesel equivalent to motivate fleets to purchase them. Based on the lessons from the Volvo Low-Impact Heavy Green Transport Solution (LIGHTS) project, the experience of every truck fleet is different, resulting in a different calculation of the TCO based on the existing power available at their site, the charging rates by their utility, and the availability of purchase incentives to help offset the significantly higher upfront cost.

\section{Nontraditional Transactional Actors}

Traditionally, the acquisition of a new truck has been a relatively simple transaction between the buyer, seller, and potentially a third-party financier. Understanding customer needs is fundamental to building market demand. Original equipment manufacturers (OEMs) consult regularly with fleets to assess technology impacts on fuel economy, driver comfort, and operational efficiency. With the advent of electric trucks, OEMs and fleets will need to consider additional factors such as range and its relation to changing duty cycles and payload, service and repair needs, cost and availability of charging infrastructure (private and public), and charging rates, to name a few.

Similar to the emergence of natural gas trucks, addressing the aforementioned factors will necessitate engaging nontraditional actors in the commercial trucking market such as electric utility companies, charging station providers, local permitting authorities, etc. Electric utility companies have limited knowledge of commercial fleet operations and needs, and the electric grid impacts from charging electric trucks/fleets. California utilities have led their industry in providing support for offsetting the cost of infrastructure needs through "make-ready" programs; however, similar programs are beginning to emerge in other states such as New York and Georgia [8]. Local utilities need to be engaged early in the process when fleets are considering electric trucks for their operations, but they are not the only charging stakeholder. As this nascent market develops, fleets must wade through a confusing overlap of actors providing hardware, software, and customer-facing solutions that are flooding the market as each seeks to build its niche and competitive advantage. Fleet managers are forced to work with new suppliers and understand new terminology for charging levels, types, and standards. Fortunately, OEMs can help fleets through this maze, as many have developed internal teams meant to help educate their customers.

Finally, local, state, and national policymakers will have a newfound influence on purchase decisions and product acceptance given their role in creating funding incentives to offset higher vehicle and charging equipment costs, issuing construction permits for charging infrastructure deployment, and public utility system upgrades. These new factors in the wide-scale rollout of electric trucks will forever change the traditional bilateral commercial transactions between OEMs and fleet owners. As OEMs and fleets lose control 
over the impact of their decisions, policymakers will have responsibility for building greater regulatory flexibility to account for the growing influences that are beyond the control of the regulated entities. In California, a zero-emission vehicle sales mandate has been adopted, and several other states have announced their intention to adopt California's regulation in support of their own air quality and climate change goals [9], yet these actions are adding to the concern and uncertainty in the trucking industry, in part because they are being evaluated through an ill-fitting frame of reference (i.e., the electric car market) and fail to account for the market realities of commercial trucks. This has the potential to inhibit, and even delay, the adoption of electric trucks in the marketplace.

\section{Volvo Low-Impact Green Heavy Transportations Solutions (LIGHTS)}

According to Volvo Group CEO Martin Lundstedt, "Partnership is the new leadership" [10]. This sentiment was borne from Volvo Group's participation in "ElectriCity," a partnership launched in 2013 with the city and regional public agencies, the private sector, and academic institutions to promote sustainable and electrified travel and transportation [11]. Although originally focused on public transport and the first all-electric bus route with indoor stations in Gothenburg, Sweden, ElectriCity's scope has been expanded to include other forms of electrified transportation and related services, including high-power charging stations, urban planning, and electric truck demonstrations.

This successful model was the inspiration behind the Volvo LIGHTS project (see Figure 1), an extraordinary partnership of 12 private and public organizations to introduce heavy-duty all-electric trucks and revolutionize freight facilities in Southern California [12]. In addition to Volvo Trucks North America, other project partners include private fleets, government agencies, ports, community colleges, a utility company, a research university, community leaders, and equipment suppliers, all working together to create an ecosystem to propel battery-electric freight movement beyond the demonstration phase into a widespread reality.

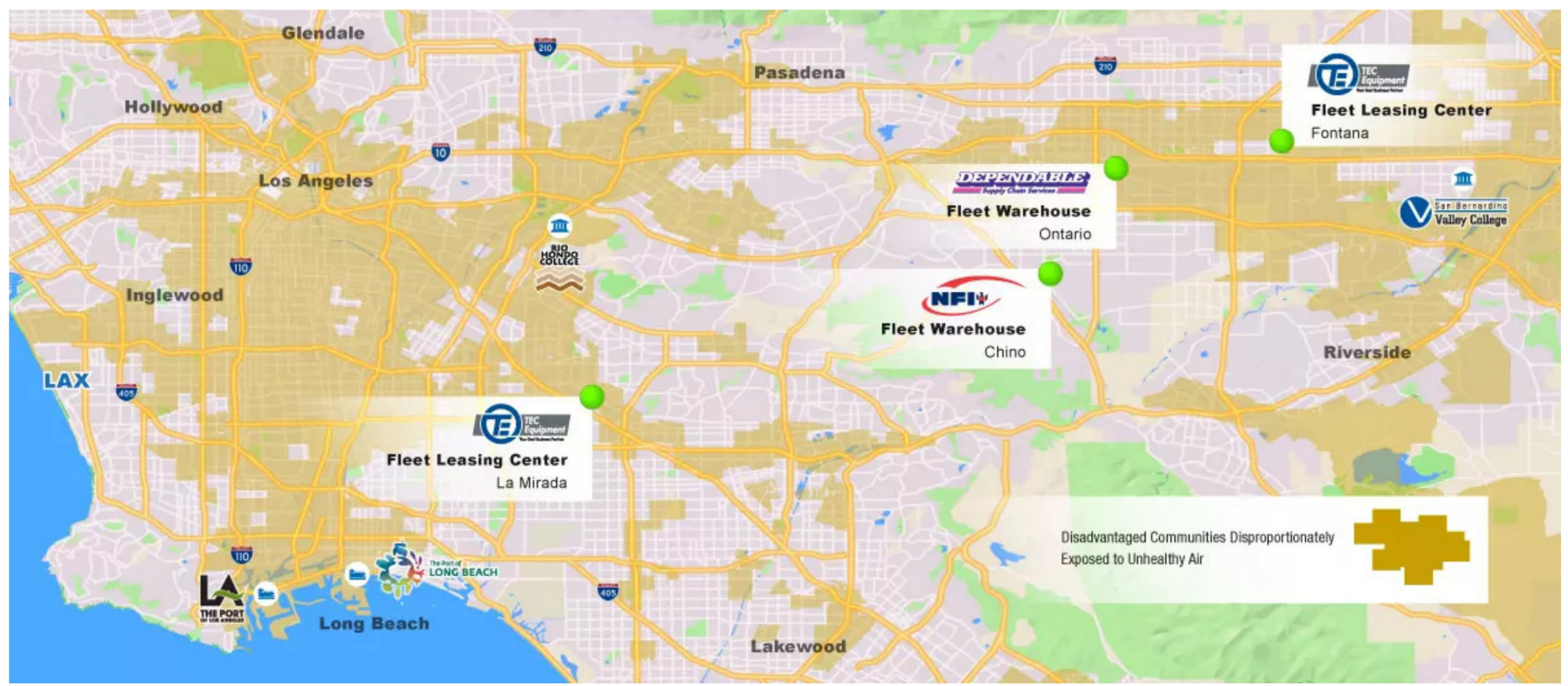

Figure 1. The Volvo LIGHTS project is taking place throughout the greater Los Angeles region. 
Volvo LIGHTS was launched in 2019 to test critical innovations in vehicle technologies, install charging infrastructure, and establish the groundwork for an electric truck sales and service network. The project is delivering 25 battery-electric trucks of varying configurations, 29 battery-electric freight handling vehicles, 58 vehicle chargers, a $1.8 \mathrm{MW}$ solar installation, and two new training curricula in nearby community colleges. The project will continue until March 2022, but already lessons are being learned, which can help ease and accelerate the experiences of other communities preparing for this paradigm shift.

\section{Keys to Success: Education and Communication}

Most individuals are familiar with the "telephone game," where the first player whispers a message in the ear of the second player, who whispers it in the ear of the third player, etc. This continues until the message reaches the last player, who recites it out loud to the whole group. The first player then compares the original message with the final version. Although the objective is to pass the message without it being changed along the way, the enjoyment comes from the extreme difficulty and funny distortions that often result. Usually, the message distortion is directly proportional to the number of players. While not a perfect analogy, the "telephone game" and efforts to introduce electric trucks in the marketplace bear similarities in terms of dependence on others and the resulting higher propensity for miscommunication.

As explained above, and witnessed thus far during the Volvo LIGHTS project, close cooperation among the diverse project stakeholders is critical because no single entity can unilaterally deliver the project. Many of the project partners have no previous experience working together (at least in the context of traditional commercial transactions). This presents additional challenges in terms of establishing common best practices and achieving project milestones. Overcoming these challenges requires education and teamwork. A first step to establishing a common baseline of understanding is education.

Compared with diesel trucks, electric powertrains are vastly different in terms of their parts. A common perception is that electric trucks will have fewer moving parts and are therefore less technically complex than diesel- and gasoline-powered trucks. Although true on one level, electric trucks also have highly specialized components, such as battery systems, advanced power management software and computing systems, regenerative braking systems, and high-voltage electrical systems, requiring the development and implementation of appropriate training modules for the safety of service technicians. It should be noted that contrary to some conventional wisdom, the intense use that comes from "normal" commercial vehicle operation means electric trucks will need regular maintenance and service. That service is potentially less intensive than traditional internal combustion engine vehicles, but data will only be developed after the deployment of a sizeable quantity of electric trucks in revenue service.

On 3 December 2020, Volvo officially launched its VNR Electric Class 8 truck model (shown in Figure 2) for sale in the US and Canada [13]. The first commercial sales have been announced and Volvo dealerships have undergone the necessary investments and training to be certified for diagnosing and repairing electric trucks. To help provide an educated workforce, Volvo LIGHTS project partners Rio Hondo and San Bernardino Valley Community Colleges instituted training programs for the next-generation workforce [14]. 


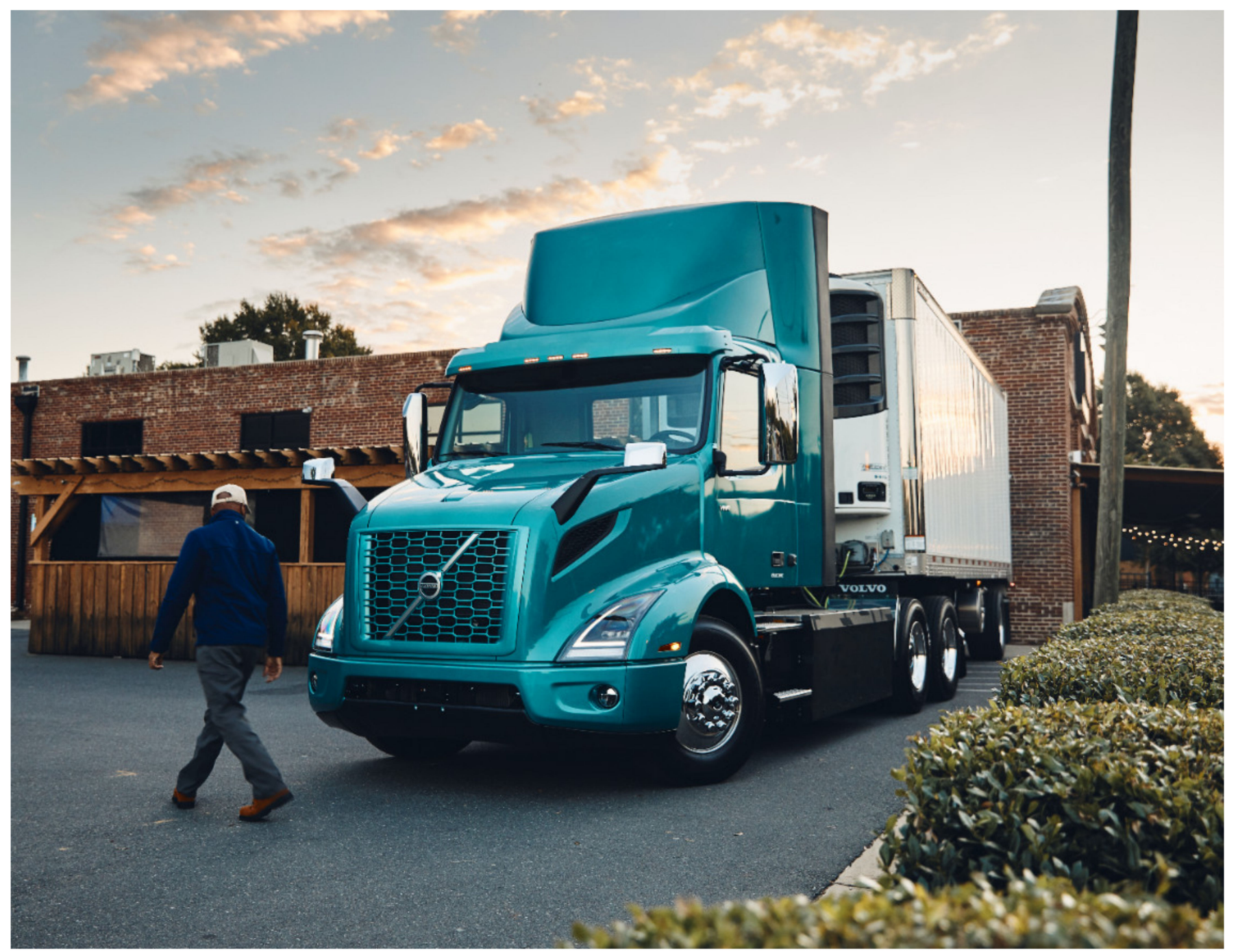

Figure 2. The Volvo VNR Electric model is currently being used in day-to-day, revenue-generating customer operations.

As noted previously, truck OEMs have always worked closely with customers to inform their product development and build brand loyalty. However, this principle will become exponentially more important with the widespread introduction of electric trucks. Not all trucks are created equal. Manufacturing specs such as gross vehicle weight rating, gross axle weight rating, transmissions, engine, tires, electrical and air systems, and cab configuration can vary greatly to meet business needs based on geography, duty cycles, and payloads. With the advent of electric trucks, truck manufacturers will need to understand commercial fleet needs and business models even more comprehensively as limited onboard energy and availability of charging affect the range, charging frequency, operational duty cycle, and route optimization for maximizing uptime. Electric powertrains present a whole new "ball of wax" that could lead to new business models for both truck manufacturers and fleets.

In addition to the technology and business implications, it is equally important to understand partner motivations and frames of reference driving different actions and decisions (see Figure 3). Most business transactions are profit driven, providing a quality product for a reasonable cost. The shift to electric trucks will not change this, yet the addition of new actors with different motivations will complicate and potentially impinge upon usual timelines. For example, utility companies and local regulators prioritizing traditional ratepayer interests or concerns for community engagement may inadvertently challenge commercial fleet demands for expeditious grid upgrades and infrastructure 
permits. The key to overcoming potential friction or delays will require sensitivity and clear communication among these stakeholder groups.

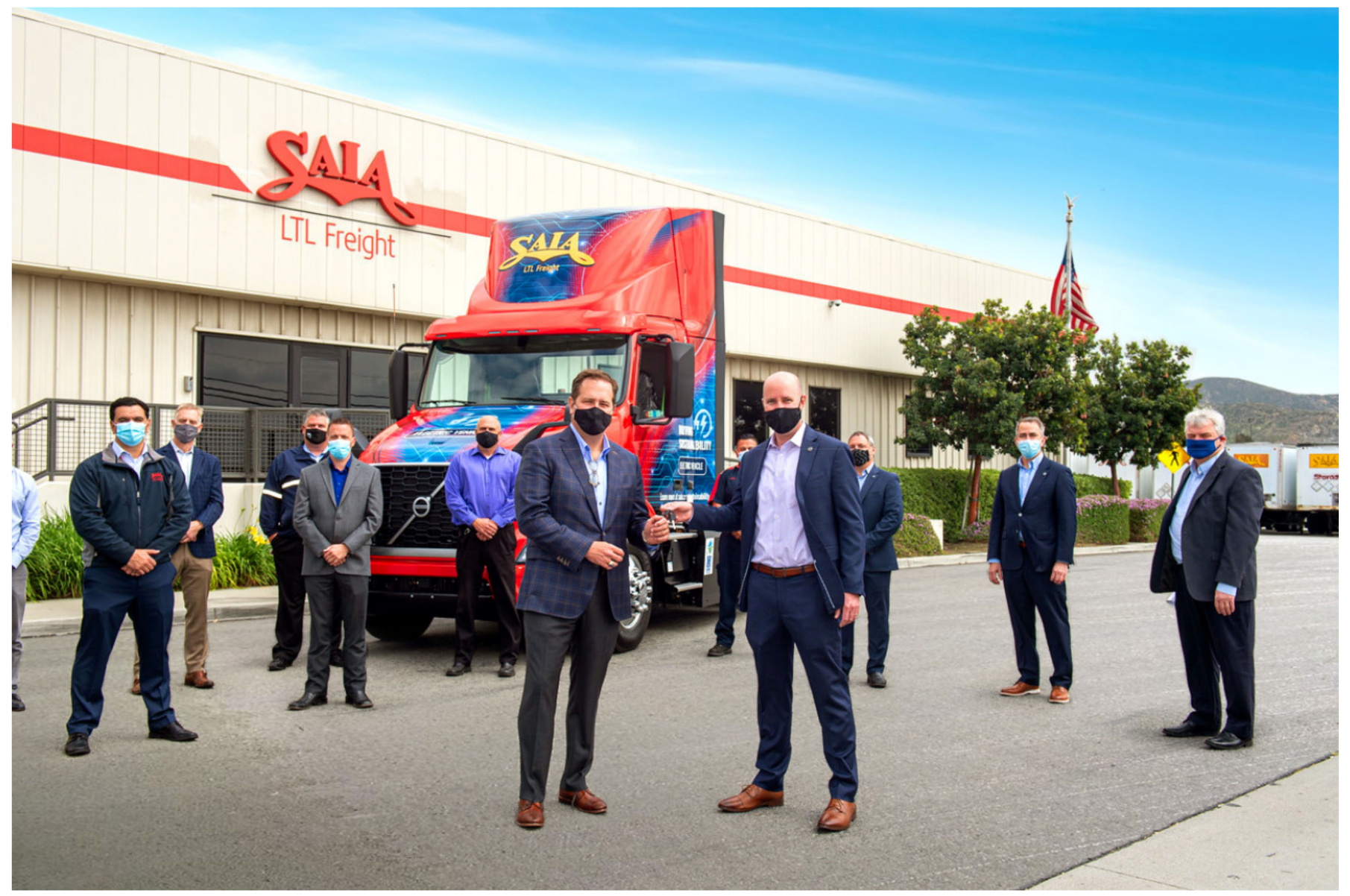

Figure 3. Saia executives, drivers, technicians, and Volvo Trucks North America (VTNA) representatives during Saia's first Volvo VNR Electric delivery, where VTNA representatives explained details of the truck and its operation to the SAIA team.

In the early days of this paradigm shift to electromobility transport solutions, it will be important to build that common baseline of understanding through the education of all stakeholders. The state of California is eagerly trying to expedite this shift to electric vehicles broadly and to trucks more specifically. However, these efforts have led, not unexpectedly, to frustration, vilification, and impatience among many stakeholder groups. Some interest groups and policymakers have been critical of the reticence on the part of utility companies, commercial fleets, and truck manufacturers to support a quicker transition to the use of electric trucks. At the same time, some of these same entities can become frustrated and dismissive of these interest groups and policymakers for their ignorance of operating business challenges. Overall, such sentiments are exacerbated by a failure to appreciate the complexities of this paradigm shift and a sensitivity to the pressures and realities of each stakeholder's frame of reference.

As this paradigm shift continues to unfold, education will have to be supplemented by strong and effective communication practices to help facilitate learning, broaden perspectives and build patience. On a project level, the integration of electric trucks in a fleet is a multistep process. Education and planning can expedite the process, but there will be obstacles and challenges only some of which could have been foreseen. What challenges do warehouse operators face to installing charging infrastructure if they lease rather than own the property? If a fleet uses trucks for both longer and shorter distance deliveries, do they need to consider new route configurations and related truck utilization to account for 
charging demands? Can a fleet access public funding incentives and count on utility-timing estimates to ensure the infrastructure is available when electric trucks are delivered and the cost to the business will not exceed the budget increase that was expected? Finding answers to these questions will require teamwork, respect, and patience as unfamiliar stakeholders depend on and leverage partner experience to navigate unfamiliar environments.

In many cases, it may be the community leaders, defined broadly, who hold the key to a project's success. Electricity as a fuel depends on utilities that are regionally based. Power upgrades will have an impact on ratepayers within that community and infrastructure expansion will require local permits. Offsetting the initial high cost of new technology, if desired faster than the current "business-as-normal" trajectories, will require government provisions of incentive funding, tax breaks, or other policy mechanisms to move the market. Citizens want clean air, a strong economy, and a healthy community. Officials at all levels of government need to be responsive to all stakeholder interests, and the utilization of what is seen as a public good (electricity) gives them more influence over industries using that good (trucking) and more responsibility to understand and resolve conflicts among all stakeholder interests.

\section{Lessons from Volvo LIGHTS}

Since the project began more than a year ago, Volvo LIGHTS partners have invested thousands of hours in pursuit of early project milestones. In some cases, projected timelines were exceeded, such as the arrival of the first five trucks in the state of California. In other cases, such as the installation of charging infrastructure, there were delays. Projects such as Volvo LIGHTS are revolutionary launching pads for electromobility solutions and not "business as usual." Delivering project milestones necessitates project partners and other stakeholders to be nimbler with their processes. Below are some of the lessons learned over the course of the project.

1. Charging infrastructure deployment will take time: One of the most important lessons is the need to anticipate delays in charging infrastructure installation in order to coincide with vehicle delivery. For instance, early steps were taken in the project to understand power needs and develop site plans for the infrastructure installation. Nevertheless, when the first five electric trucks were delivered in California, there were only two charging stations available (shown in Figures 4 and 5), and the timeline for others had been delayed. Fleets need to start the site and equipment planning early and navigate challenges by being flexible. Additionally, proactively engaging the utility company and city agencies early and preparedness for collaborating with nontraditional partners will further mitigate delays and help calibrate fleets' own expectations regarding the timeline for the infrastructure deployment. Additional challenges can arise if a warehouse is leased rather than owned, requiring consultation with a landlord on how to handle costs, easement rights, and commitments related to infrastructure installation. Clear and timely communication will again be key. Fleets or warehouse operators should consider contracting an experienced turnkey installer and appointing a dedicated onsite project manager. Lastly, freight facility modernization projects having larger scopes-a site having chargers for electric trucks, passenger cars, yard equipment, onsite energy harvesting and storage systems, etc.-will need more coordination and resources to successfully deliver the project.

2. Early stakeholder engagement and coordination are essential for infrastructure deployment: Fleets have never really had to plan for the fueling of their diesel vehicles, and this new need to plan is even further complicated by the fact that it necessitates unprecedented cooperation with new stakeholders who are unfamiliar with the trucking industry. The utility company will install new lines and determine load demands on the grid when there is a fleet of electric trucks. Before this work can be carried out, the requisite permits must be acquired from city and county officials, which have unique codes, requirements, and interpretations. 
Whether a project is a renovation, addition, or new construction, all facility designs are subject in some form to compliance from local permitting agencies. To minimize delays and misjudgments, it is advantageous to coordinate interactions between the design staff across utility and local permitting staff. This will help mitigate redundancies and ensure a code-compliant design, so any civil and electric site work that follows could be streamlined and made more efficient. Building relationships with local officials and community leaders may also help alleviate unnecessary bottlenecks in the permitting process.

Careful coordination with city planning will help identify and resolve any issues around site selection, especially in the case of public charging stations. State priorities and existing utility tariff laws may unwittingly hinder the deployment of charging stations, especially in the case of semi-public and public sites. This may take several months and necessitate cooperation with other stakeholders such as the Public Utilities Commission, utility companies, and the state legislature.

The utility company can also provide guidance on taking advantage of demandresponse pricing to help commercial fleets save money by charging during off-peak periods. Early engagement with all these stakeholders can help clarify costs and timeline ramifications for the overall project.

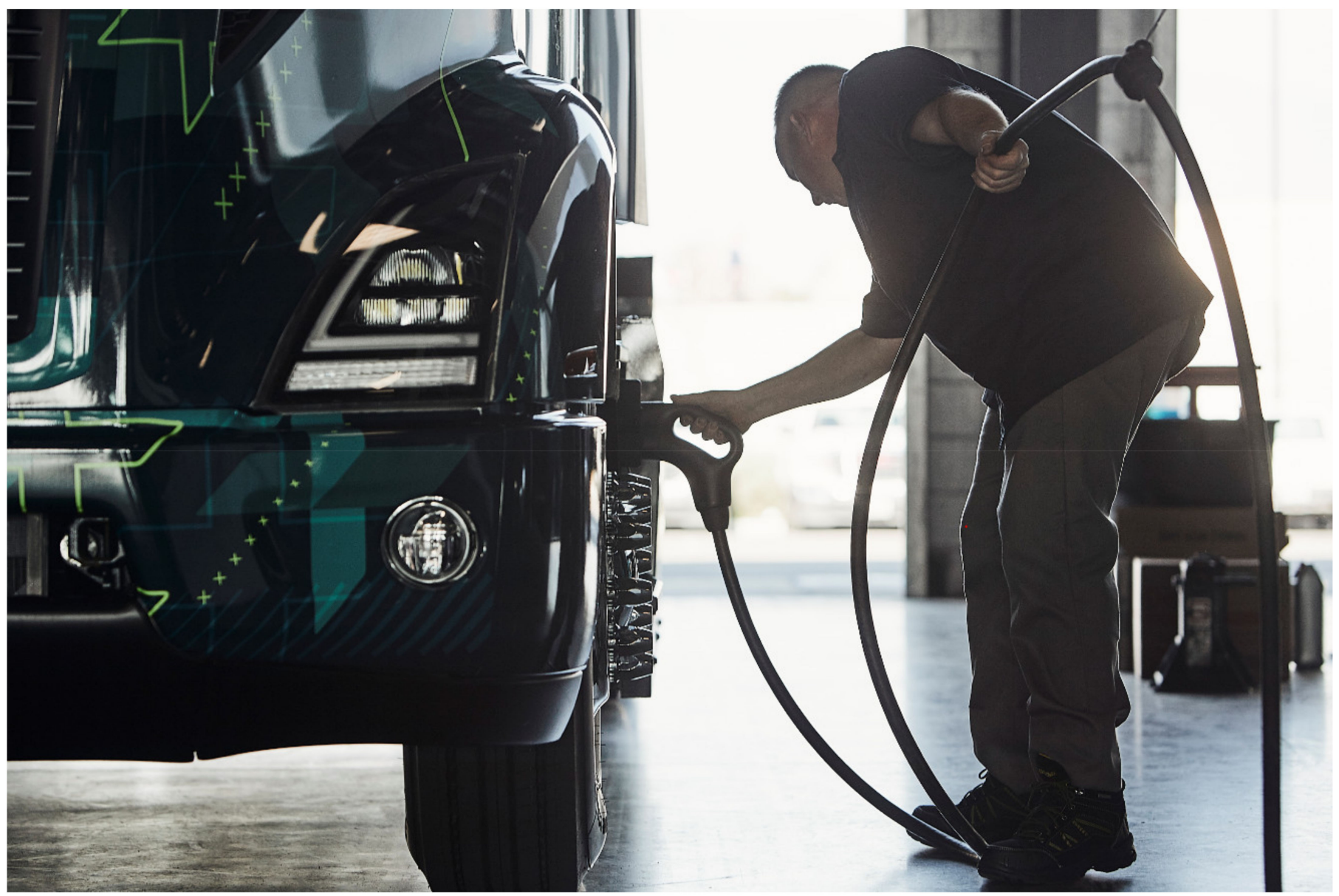

Figure 4. A Volvo VNR Electric is being plugged in to charge up. 


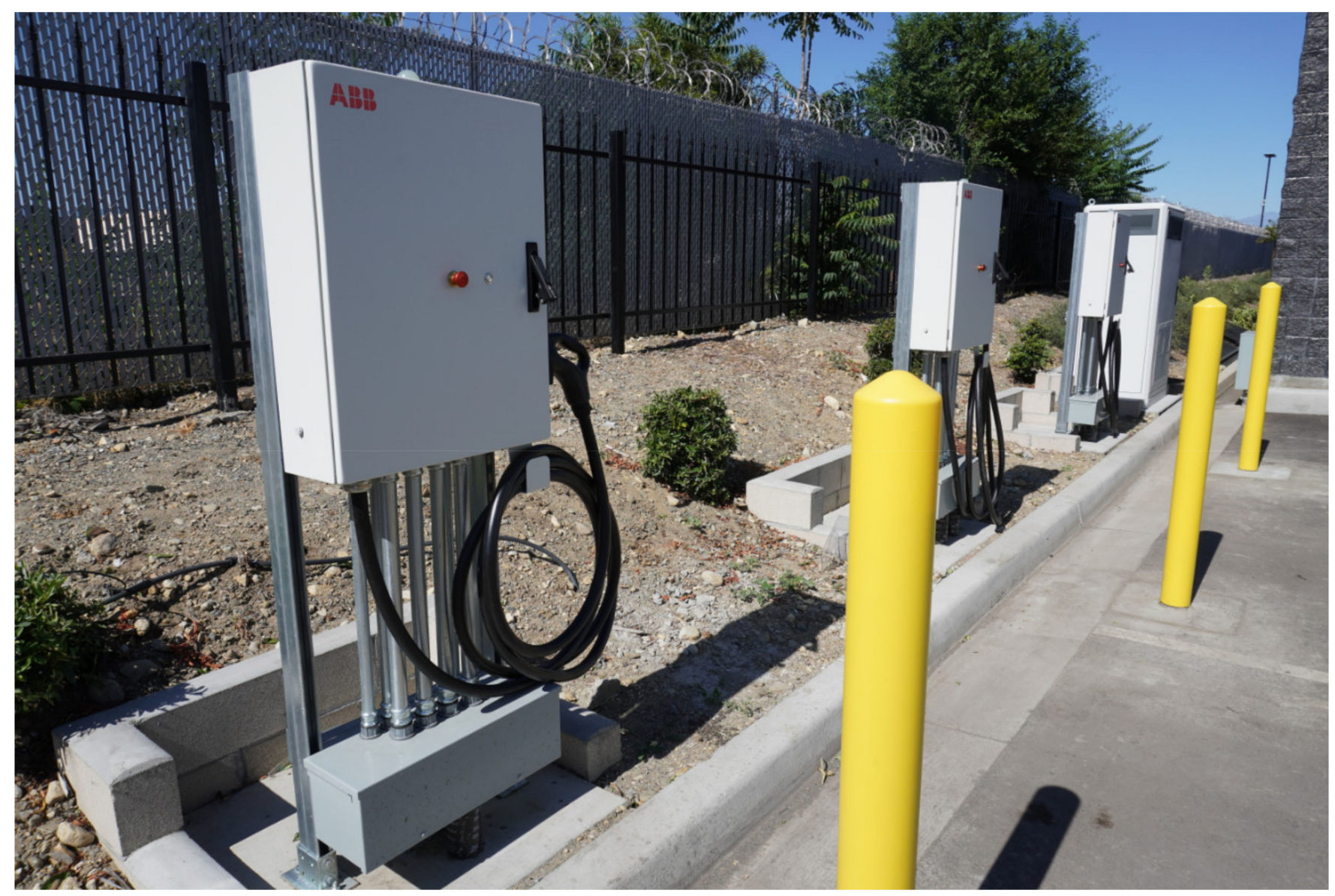

Figure 5. An example of outdoor charging infrastructure.

3. Consider the entire charging ecosystem: The transition to an electric fleet is not just about selecting trucks for a one-to-one replacement of existing diesel trucks. This transition requires a holistic approach that includes figuring out the charging solution that will best serve fleet needs in the near term, how it can be scaled up, and how it impacts the business's bottom line. To achieve this, fleets must consider their own business goals, strategy, and limitations, and evaluate a number of charging optionsfrom mobile chargers to high power and efficient chargers to future-proofing charging solutions, to site solutions that may include onsite energy generation and storage. Most fleets prefer to start out with one or two electric trucks to avoid large capital investments and try to understand the impacts of this transition on their overall business operations. This creates a unique challenge for these early adopters where they must decide between a powerful truck charger (e.g., a $150 \mathrm{~kW}$ charger) (shown in Figure 5) that will charge up $80 \%$ of the truck within $1.5 \mathrm{~h}$ and a less powerful one (e.g., $50 \mathrm{~kW}$ charger) (shown in Figure 4) that will take about $8 \mathrm{~h}$ to achieve the same state of charge. The more powerful charger may entail additional capital investment costs in the form of civil and electrical upgrades that cannot be justified at such an early stage but could provide a faster charging solution. On the other hand, the less powerful charger could be more affordable but significantly delay the availability of power and usage of the truck. 
It is hard to know how to manage the tradeoffs, and therefore, one might want to consider a good mix of high- and low-power DC fast-charging stations. Most commercial sites have three-phase power, and this might motivate having high-power AC charging stations at a fraction of the cost of DC fast-charging stations (see Figure 6). Ultimately, upgrading infrastructure can be very expensive, especially if one does not plan for it; therefore, it is important that any chosen solution allows for the easiest and least expensive means for adding charging power or chargers at a future date. However, even with careful planning, technology will continue to improve and enable new options for onsite renewable energy generation and storage, reusing electric truck batteries, and deploying alternative charging options (such as using wireless charging). In the end, it is prudent to work closely with your OEM to evaluate all options carefully and keeping in mind the long-term business vision to ensure that the charging infrastructure and other freight facility enhancements can scale with business growth.

4. Workforce development is needed: Electric trucks offer many advantages for fleets and the environment, but similar to the transition to a digital world, there is a learning curve for the workforce that includes drivers, technicians, fleet staff, first responders, charging solution providers, and utility companies.

- Drivers: Not unlike their diesel predecessors, driving style can have a significant impact on a truck's fuel economy, or charging range. This becomes even more important in these early days given the lack of public charging networks and limited opportunity chargers. Driver training is critical to maximizing the regenerative braking benefits, even for experienced drivers, potentially adding between 40 and $80 \%$ power back to the battery to extend range. Driver performance can help extend power in the battery; however, the battery state of charge can also be a function of the routes being driven. Even the best driver can only gain as much power from the regenerative braking as the chosen route allows. Length of the route between stops, topography, and weather conditions all impact the use of brakes and the draw of power on the battery, thereby further underscoring the importance of route optimization from a charging and duty cycle perspective.

- Technicians: Trained technicians are critical for boosting the uptime of electric trucks and chargers. The advanced electric drivetrains and increasingly sophisticated technology on electric trucks will require a highly skilled and specialized workforce to support, maintain, and repair them (see Figure 7). Vehicle and charger technicians will require new, advanced skills and a supportive training ecosystem to successfully address the evolving needs of an industry's technology in transition. Therefore, before acquiring trucks, it is important to have either trained electric truck service technicians on staff who can also do some basic troubleshooting with the chargers and/or ensure that a local dealer is prepared to help address problems as they arise.

- Fleet staff: Fleet facility or warehouse projects involving the addition of electric trucks and charging infrastructure into existing fleet operations are complex. While the OEM or technology providers will have experts who can assist in the vehicle requirements and optimization of operations, it is recommended to have a dedicated staff person identified to coordinate all aspects of the project. Trucking companies are typically focused on the daily delivery of goods with excellent service levels. Therefore, staffing a dedicated fleet project manager is needed to oversee the site implementation.

- First responders: An important consideration for the implementation of this new technology is the potential hazards that may result, and how first responders will address and mitigate those hazards. Without appropriate training and education support to firefighters and other first responders, the electric truck drivers and first responders themselves could be at increased risk. Questions or misconceptions about the safety of electric trucks in emergency situations will hinder the electric truck market growth. To respond to this challenge, the onus is on the OEM (and/or the technology provider) to develop appropriate training and make it available to first responder communities, in a variety of formats and mediums. 
- Charging solution providers: Uptime for fleets is a critical metric and performance issues with chargers that will hamper the ability to charge the trucks need to be diagnosed and addressed in almost real time. Additionally, most early adopter fleets will not have the technical background, nor prior experience using and/or troubleshooting this new equipment, and therefore, charging solution providers need to staff up and support the fleets during handoff and during the early days to aid a smooth transition and good experience for the fleets.

- Utility companies: Utilities need to recruit (and train) staff to increase electric truck adoption among their (commercial) customers. There is a need to conduct analysis and research related to medium/heavy duty truck adoption and translating that information into digestible presentations and formats that help advance market adoption. Utility companies need to foster engagement with OEMs, charging station companies, and relevant industry groups to build robust indirect sales channels that will support the market growth by instilling confidence and support for their customers. To this end, major utility companies are reorganizing and creating separate business units to handle transportation electrification initiatives and staffing up to support their customers.

5. New partners must prepare to support the unique needs of the trucking sector: Fleet willingness to adopt the technology will depend on the degree to which diesel vehicles' convenience can be matched. Trucks must have maximum uptime, which necessitates a sensitivity from the utilities and infrastructure providers. These new stakeholders are unfamiliar with the full implications of downtime for trucking companies and need further education to understand the impact of their service on new customer business. Utilities can help reduce fleet apprehension by mitigating the timelines for charger power $\mathrm{ON}$ and establishing a single point of contact at the utility company to handle all needs at the concerned site (from truck and yard equipment chargers to alternative energy generation and storage systems). Similar customer service features and prioritization from charging equipment suppliers will help fleets feel more comfortable about fully integrating electric trucks as full replacements for diesel in their fleet. The heavy-duty vehicle charging industry is still nascent, and it will take time for stakeholders to understand the impact of this transition on their customers and revamp their business practices.

6. Government and public agencies can help reduce the total cost of ownership (TCO): As with any new product or technology offering, early generation zero-emission vehicles have limited availability and are exceedingly expensive. Unlike consumer goods, where innovators and early adopters are more risk tolerant and motivated by novelty and status, fleets purchasing early battery-electric trucks view them through a competitive lens relative to their diesel vehicles. Purchase decisions are more rational and less emotional, requiring a total cost of ownership calculation. 
Installation (incl. design, construction, procurement, and energization) time (mos.)

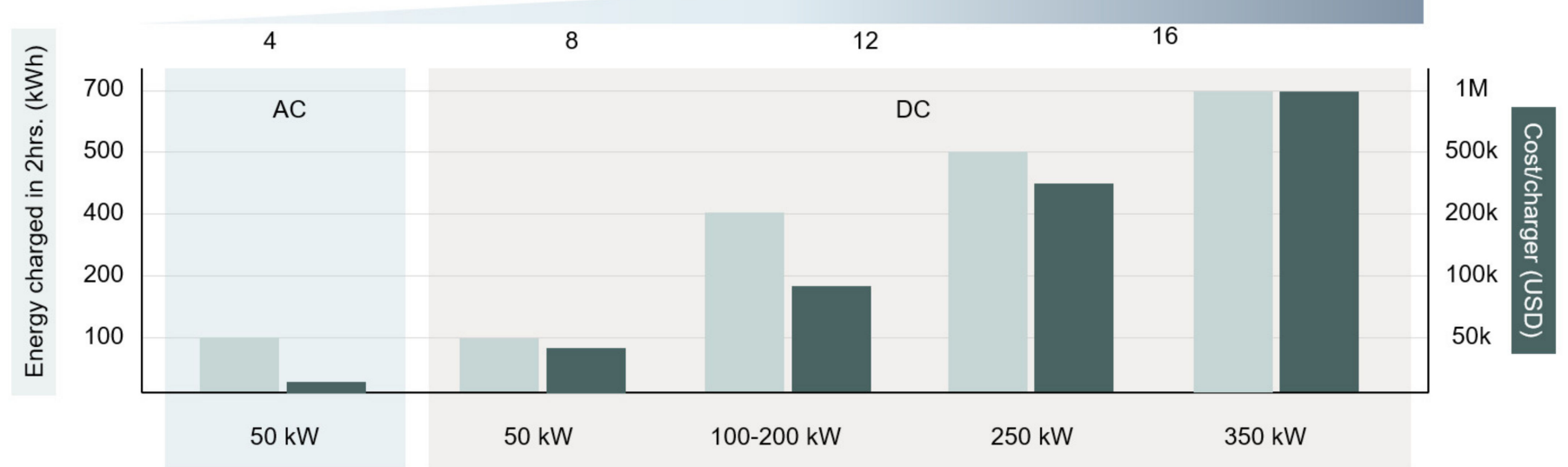

Figure 6. DC fast charging offers more power but is more expensive and time consuming to install and operate.

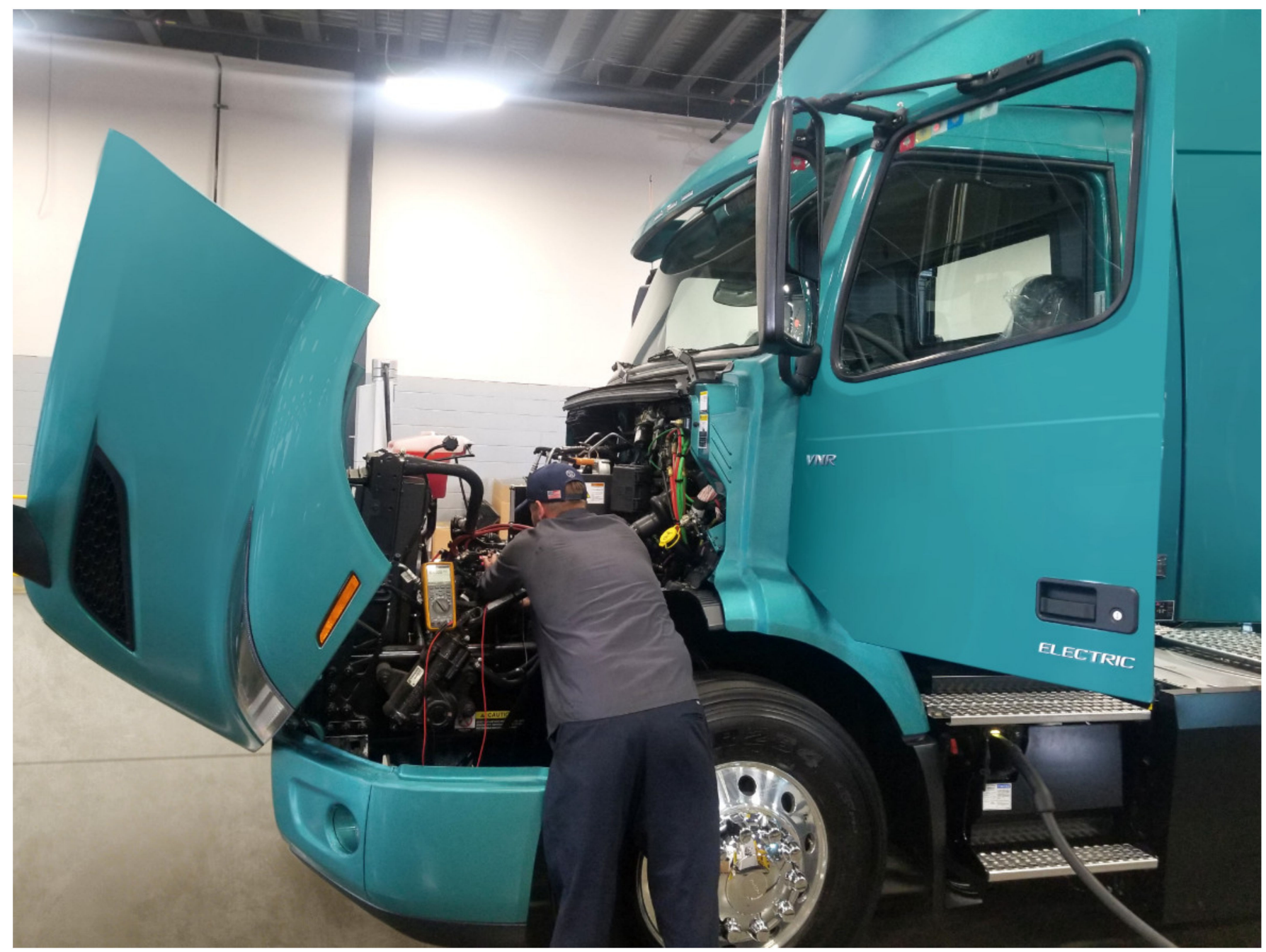

Figure 7. A specially certified technician at a Volvo Trucks dealership performs maintenance on a Volvo VNR Electric. 
Higher purchase prices (currently more than double their diesel counterparts) must be offset with lower operating or maintenance costs, but it is hard to assess future costs with such unproven and quickly developing technologies. Until the longer-term operational savings are assured, fleets will require purchase incentives to offset those initial higher purchase prices to improve the business case for their investment. California has led the country in public funding by offering multiple types of purchasing assistance for both vehicles and charging infrastructure. Additionally, multiple utilities provide "makeready" charging assistance to help pay the cost of bringing sufficient electric power and stability to the customer site. Several other states have begun providing similar funding programs (New Jersey, New York, Georgia); however, they fall significantly short of California's funding levels and lack any meaningful coordination between vehicle and infrastructure funding.

Beyond the initial purchase price, the next most important financial consideration facing fleets is fuel costs. Several studies have highlighted the volatility of global diesel prices and the relative security and stability of having a domestic fuel source. While the source of electric fuel is more secure, the price and availability of electricity also have their share of volatility.

Electricity rates will replace diesel prices in the calculation of trucking's secondhighest cost (24\%, behind 33\% for driver wages) [15], yet the lack of transparency and inconsistency of costs will complicate early TCO calculations. During the Volvo LIGHTS project, charging costs fluctuated more than $500 \%$ depending on the time of day and seasonal usage. Certainly, fleets can mitigate this price divergence through planning and managing the time and speed of charge, but this becomes more complicated as they travel across state lines or utility jurisdictions. Government policies and programs that provide certainty, transparency, and incentives can help fleets measure the risk of adopting this new technology, which will, in turn, help them to better manage it and be more accepting of it.

7. It is not just about the range: A variety of different businesses are utilizing the Volvo VNR Electric truck in commercial operation as part of the Volvo LIGHTS project. These companies have hauled customer freight for 80-150 miles depending on the duty cycle, haulage, etc. Assessing the viability of using electric trucks in fleet operations, especially in these early days given the state of onboard energy storage systems and lack of charging networks, requires looking beyond a battery range figure. A more practical approach is to identify customer routes and applications that are best suited for electric trucks by working together to understand a fleet's operational details. In other words, selling electric trucks will be very different compared to diesel trucks, and the industry (the OEM, fleets, and dealers) has a learning curve to be as successful.

\section{Conclusions}

Advances in electric powertrain and battery technologies have the potential to transform the traditional commercial trucking sector, reducing the emissions and noise footprint of goods movement, and bringing novel asset ownership and business considerations to fleets. These advanced technologies will demand new expertise; novel training programs are needed to prepare the next-generation workforce for the challenges of electric trucks. Skillful preparation and change management within the trucking sector will be critical in light of the industry's importance to the broader US economy given that the trucking industry moves nearly $71 \%$ of freight tonnage in the US [16] and employs about 1 of every 15 workers in the nation [17].

As illustrated through the Volvo LIGHTS project, it will take more than just the truck to switch from diesel to electric power. This paradigm shift will lead to greater interdependence among a wider number of stakeholders. For instance, fleet operations will need to be more connected (than ever before) with maintenance technicians, drivers, and management to maximize vehicle range and efficiency, configure charging strategies, and implement the necessary charging infrastructure. Education and communication are 
key to fostering these close collaborations among the various stakeholders and enabling them to be pioneers together.

Electric trucks are coming to the market, and actions can be taken to help accelerate their penetration. First and foremost, fleets make decisions on the lifetime costs of buying and operating trucks. Electric trucks require more expensive, high-power charging infrastructure than cars, and this requires greater time, cost, and planning for fleets. Governments and public agencies can help alleviate risk through financial incentives and policies that require greater coordination and transparency among key stakeholders. Electric trucks are here, and several major truck manufacturers agree that they are central to the industry's future viability. It is essential to encourage all stakeholders to work proactively together and adjust their frame of reference to make this paradigm shift a reality. The transition to electric powertrains will be very different from the introduction of emissions control technology in 2004, 2007, or even 2010, when diesel exhaust fluid became part of the fuelling protocol. Change can be difficult, but Volvo LIGHTS is proving that education and communication, through earnest collaboration, will pave the way for electromobility solutions in the commercial trucking sector.

Funding: Volvo LIGHTS is part of California Climate Investments, a statewide initiative that puts billions of Cap-and-Trade dollars to work reducing greenhouse gas emissions, strengthening the economy, and improving public health and the environment-particularly in disadvantaged communities. The total project cost is USD 90 million, with a funding award of USD 44.8 million.

Institutional Review Board Statement: Not applicable.

Informed Consent Statement: Not applicable.

Acknowledgments: The authors thank Keith Brandis, Jennifer Edwards, Mary Beth Halprin, Fredrik Klevenfeldt, John Mies, Jonathan Miller, and Roopa Shenoy for their careful proofreading and feedback.

Conflicts of Interest: The authors declare no conflict of interest. The funders had no role in the design of the study; in the collection, analyses, or interpretation of data; in the writing of the manuscript, or in the decision to publish the results.

\section{References}

1. Alternative Fuels Data Center. Available online: https://afdc.energy.gov/data/ (accessed on 24 July 2021).

2. Public Transportation Fact Book. Available online: https://www.apta.com/research-technical-resources/transit-statistics/publictransportation-fact-book/ (accessed on 24 July 2021).

3. Diesel Technology Forum. For Earth Day 2019, the Customer is Always Right. Available online: https://www.dieselforum.org/ policyinsider/for-earth-day-2018-the-customer-is-always-right (accessed on 24 July 2021).

4. Diesel Technology Forum. Available online: https://www.dieselforum.org/news-and-resources/diesel-resource-library/dieselresource-library (accessed on 24 July 2021).

5. Diesel Technology Forum. About Clean Diesel—Why Diesel Isn't Dirty. Available online: https://www.dieselforum.org/aboutclean-diesel/why-diesel-isn-t-dirty (accessed on 24 July 2021).

6. Diesel Technology Forum. Diesel Drivers-Fuel Locator. Available online: https://www.dieselforum.org/diesel-drivers/fuellocator (accessed on 24 July 2021).

7. Daimler Trucks North America, Portland General Electric Open First-of-Its-Kind Heavy-Duty Electric Truck Charging Site. Available online: https:/ / www.prnewswire.com/news-releases/daimler-trucks-north-america-portland-general-electric-openfirst-of-its-kind-heavy-duty-electric-truck-charging-site-301274147.html (accessed on 24 July 2021).

8. Georgia Power. Available online: https://www.georgiapower.com/business/products-programs/business-solutions/electrictransportation-business-programs.html (accessed on 24 July 2021).

9. Advanced Clean Trucks Fact Sheet. Available online: https://ww2.arb.ca.gov/our-work/programs/advanced-clean-trucks (accessed on 24 July 2021).

10. Cannon, J. Bright Idea: Volvo Trucks Flipping the Switch on Its LIGHTS Project. Available online: https:/ /www.ccjdigital.com/ volvo-trucks-lights-project/\# (accessed on 24 July 2021).

11. ElectriCity. Available online: https:/ / www.electricitygoteborg.se/en (accessed on 24 July 2021).

12. Volvo LIGHTS. Available online: https:/ / www.lightsproject.com (accessed on 24 July 2021). 
13. Volvo Trucks North America Demonstrates Pilot All-Electric VNR Models as Part of Volvo LIGHTS Innovation Showcase. Available online: https:/ / www.volvotrucks.us/news-and-stories/press-releases/2020/february/all-electric-vnr-models / (accessed on 24 July 2021).

14. As in Electric Vehicle and Fuel Cell Technology Technician. Available online: https://www.riohondo.edu/academics/electricvehicle-fuel-cell-technology-tech/ (accessed on 24 July 2021).

15. An Analysis of the Operational Costs of Trucking: 2019 Update. Available online: https://truckingresearch.org/wp-content/ uploads/2019/11/ATRI-Operational-Costs-of-Trucking-2019-1.pdf (accessed on 24 July 2021).

16. American Trucking Associations. Available online: https:/ /www.trucking.org/news-insights (accessed on 24 July 2021).

17. Truck Drivers in the USA. Available online: http://www.alltrucking.com/faq/truck-drivers-in-the-usa/ (accessed on 24 July 2021). 